\title{
CUP: Mit Epigenetik auf den Primarius schließen
}

\section{Hier steht eine Anzeige.}

Patienten mit unbekanntem Primärtumor wurden bisher meist empirisch behandelt. Könnte man den Primarius häufiger identifizieren, wäre womöglich öfter eine zielgerichtete Therapie möglich. Welchen Nutzen hat in diesem Zusammenhang das DNA-Methylierungsmuster der Tumorzellen?

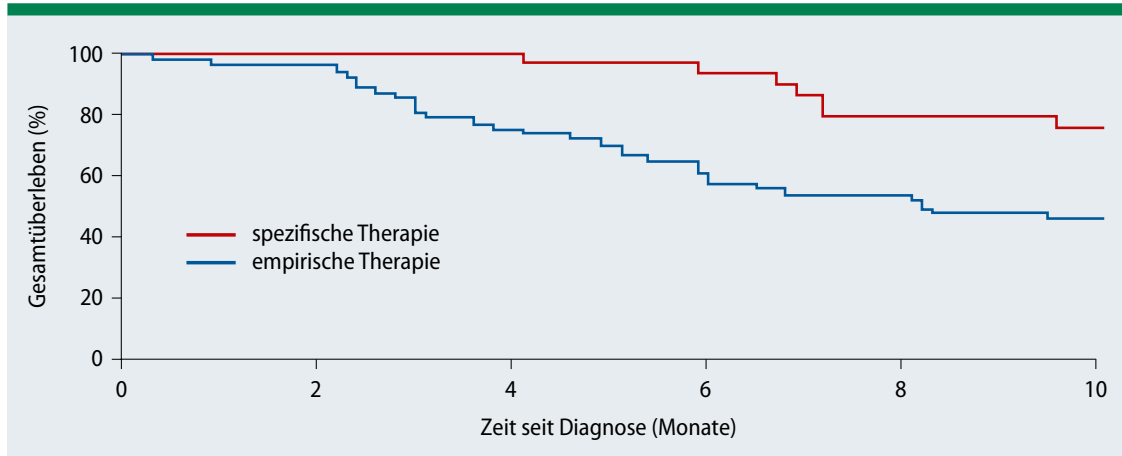

Abb. 1: Patienten lebten deutlich länger mit einer spezifischen Therapie auf Basis der EPICUP-Diagnose.

Verschiedene immunhistochemische Panels wurden für die Diagnose von CUP entwickelt, aber selbst nach der kompletten Diagnostik bleibt der Primärtumor bei circa $75 \%$ der Patienten unbekannt. Bei einigen Tumorentitäten geben per Microarray detektierte Genexpressionsprofile Hinweise zum Primarius. Eine Alternative bzw. Ergänzung könnte die Bestimmung der DNAMethylierungsmusters bieten. $\mathrm{Zu}$ diesem Schluss kommt eine spanische Arbeitsgruppe. Durch Kartierung der DNA-Methylierungsmuster von 2.790 Tumorproben bekannten Ursprungs sie repräsentierten 38 Tumorarten und beinhalteten 85 Metastasen - hatten sie basierend auf Microarray-DNA-Methylierungssignaturen (EPICUP) einen Klassifikator entwickelt. Validiert wurde dieser an 7.691 bekannten Tumorpro- ben derselben Tumorarten. Im dritten Schritt wurde der diagnostische Test angewendet, um die Tumorart von 216 gut charakterisierten CUP-Patienten vorherzusagen.

Insgesamt zeigte die Klassifizierung in der Validierung eine 99,6\%ige Spezifität, eine 97,7\%ige Sensitivität, einen $88,6 \%$ igen positiv prädiktiven Wert und einen $99,9 \%$ igen negativ prädiktiven

Wert. Bei 188 (87\%) der Patienten mit unbekanntem Primärtumor erlaubte das DNA-Methylierungsmuster eine Vorhersage zum Primarius. Eine darauf basierende tumorspezifische Behandlung ergab ein signifikant besseres Gesamtüberleben als eine empirische Therapie (Hazard Ratio 3,24, 95\%-Konfidenzintervall 1,42-7,38; $\mathrm{p}=0,0051 ;$ Abb. 1).

Fazit: Bei Patienten mit unbekanntem Primärtumor können typische DNAMethylierungsmuster des Metastasengewebes helfen, die zugrundeliegende Tumorart zu identifizieren. Dies wäre für die Therapie von Nutzen.

\section{Barbara Kreutzkamp}

Moran S et al. Epigenetic profiling to classify cancer of unknown primary: a multicentre, retrospective analysis. Lancet Oncol. 2016; 17(10):1386-95. 